\title{
Testing for Earnings Management in the U.S. Amid the COVID-19 Pandemic
}

\author{
Charles E. Jordan \\ Florida State University - Panama City \\ Stanley J. Clark \\ Middle Tennessee State University \\ Marilyn A. Waldron \\ University of Sydney
}

\begin{abstract}
Some forms of earnings management largely disappeared after SOX's implementation, including cosmetic earnings management and the upward manipulation of income to ensure that reported EPS is rounded up a penny rather than down a cent. Yet, research shows that the incidence of accrual-based earnings management increases during an economic downturn. This raises a question of whether these two types of earnings management might have reappeared in the U.S. during the unique, pandemic-driven recession of 2020. The current study tests this issue and finds no compelling evidence that either of these two easilyachieved forms of earnings management occurred overall in 2020.
\end{abstract}

Keywords: earnings management, pandemic, COVID-19

\section{INTRODUCTION}

During 2020, in the midst of a global pandemic, business as usual lost all meaning as practically overnight many facets of our society experienced drastic change. The education system from kindergarten to graduate school shifted from face-to-face to online instruction. Many churches and businesses alike shuttered their doors; a large number of those that remained open did so through the use of technology and the internet.

In April 2020, the unemployment rate in the U.S. hit 14.8\%, the highest level since such data collection started in 1948. Unlike the unemployment rate in the Great Recession that increased gradually from 5\% in December 2007 to its peak of $10 \%$ in October 2009, the unemployment rate associated with the COVID19 pandemic increased at a meteoric pace, rising from 3.5\% in February 2020 to its pinnacle of $14.8 \%$ just two months later. Even though the overall U.S. jobless rate declined after April 2020, it remained elevated at the end of the year at $6.7 \%$, which was roughly twice the pre-pandemic rate at the beginning of 2020 . Industries that provided in-person services experienced even higher unemployment rates. For example, the hospitality industry's jobless rate topped out at 39.3\% in April 2020 (Congressional Research Service, 2021).

Trombetta and Imperatore (2014) provide evidence suggesting managers' propensity to employ earnings management is associated with the amount of financial stress faced by a firm. In particular, as a 
financial crisis becomes more extreme, the likelihood that managers will utilize earnings management practices increases as well. The current study examines data during the pandemic year (2020) for the presence of two specific types of discretionary earnings management activities that regularly occurred before the Sarbanes-Oxley Act of 2002 (SOX) but disappeared for the most part after the implementation of this sweeping legislation aimed at curbing the incidence of fraudulent financial reporting existing at that time. The first type of earnings management investigated is cosmetic earnings management (CEM), which occurs when the second left digit in the income number is manipulated up so that it reaches zero and causes the first left digit to rise by one. The second type of earnings management examined relates to the upward manipulation of income to ensure the calculated EPS number is rounded a penny higher rather than lower when EPS is reported in the income statement.

Both of these types of earnings management activities are relatively easy to achieve via the use of judgments inherent in accrual basis accounting, and the economic downturn during 2020 presents an opportunity to ascertain whether managers would succumb to the financial pressures and return to their preSOX ways. Refreshingly, the results suggest that managers continued to exhibit their post-SOX unbiased reporting practices despite the pandemic-induced recession, as evidence indicates neither of these earnings management practices occurred during 2020.

\section{LITERATURE REVIEW AND RESEARCH QUESTION}

Wang and Huang (2014) note that earnings management occurs for self-serving reasons (e.g., enhanced financial performance culminating in increased remuneration for managers or the avoidance of debt covenant violations) and results in sacrificing reporting reliability. Similar to the findings by Trombetta and Imperatore (2014) discussed earlier, Wang and Huang (2014) also show that, in general, earnings management activities increase during a recession or period of economic downturn. They point out that "when firm performance weakens, managers would want to convey a message of recovery and improvement by manipulating earnings" (Wang and Huang, 2014, p. 1).

Rupkey (2020) states that while the 2020 pandemic-driven recession in the U.S. may have been relatively short (about two months officially), its effects were severe. For example, from February 2020 to April 2020, 22 million Americans lost their jobs because of shutdowns resulting from the pandemic. To put this in perspective, only 2.6 million jobs were lost in the 2001 recession and 8.6 million jobs vanished during the 2007-2008 recession (Rupkey, 2020). In addition to the unprecedented short lead time preceding the 2020 recession, Guckes (2020) observes that it is also unique in the inconsistency with which it affected various industries. For example, industries like tourism, restaurants, and air travel suffered mightily while other industries (e.g., groceries, home improvement, and recreational vehicles) managed to avoid the negative effects or even benefited from the pandemic related restrictions.

As mentioned earlier, the uncommon and unexpected economic downturn experienced in 2020 due to COVID-19 presents a rare opportunity to test for the possible reemergence of a couple of types of discretionary earnings management techniques that were commonplace prior to the major corporate accounting scandals unearthed in the early 2000s (e.g., WorldCom, Enron, Xerox, etc.) but that mostly vanished soon after. The significant reduction or disappearance of these and other types of accrual-based earnings management practices around this time is often attributed to the SOX legislation and its stiff penalties for fraudulent financial reporting that became effective in 2002 (e.g., Anin, 2021; Aubert and Grudnistki, 2014; Hossain et al., 2011).

As discussed previously, the first type of discretionary earnings management examined here is CEM, which occurs when a company engages in "a small upward rounding of reported net income, when such rounding yields an earnings number that seems abnormally larger than would be the case otherwise" (Kinnunen and Koskela, 2003, p. 40). As an example, income of \$2.96 million might be enhanced through accrual-based earnings management up to $\$ 3.00$ million. The aim of this self-serving activity is to boost by one the left-most digit in the income figure because people often focus on and base their decisions on the most influential digit in a number (Brenner and Brenner, 1982). Management would rather financial statement users remember the firm's net income as \$3 million something rather than \$2 million something. 
Research shows that CEM took place for many decades in the U.S. and elsewhere prior to SOX (e.g., Carslaw, 1988; Jordan and Clark, 2015; Thomas, 1989; Van Caneghem, 2002), but this practice largely dissipated almost immediately thereafter (e.g., Aono and Guan, 2008; Jordan and Clark, 2015; Lin and Wu, 2014).

The second form of discretionary earnings management tested during the pandemic year (2020) entails increasing income so that the reported earnings per share (EPS) number is rounded up (rather than down) one cent. FASB requires companies to report EPS in dollars and cents (e.g., \$1.12). Nonetheless, when calculating EPS the result rarely comes out to an exact penny. For example, an entity with net income for the year of $\$ 3,552,570$ and an average number of outstanding shares for the period of 9,000,000 would have a calculated EPS number of $\$ 0.39473$ (i.e., $\$ 3,552,570 / 9,000,000$ shares). Using a normal rounding procedure, this would be rounded down and reported in the income statement as EPS of $\$ 0.39$. A relatively inconsequential increase in income of $\$ 2,430$ to $\$ 3,555,000$ would boost calculated EPS to $\$ 0.395$ $(\$ 3,555,000 / 9,000,000$ shares $)$, which would now be rounded up and reported as EPS of $\$ 0.40$. Thus, an almost undetectable level of income manipulation can cause EPS to be rounded up a cent rather than down a penny. This type of earnings management could produce positive benefits for a company that is close to meeting its earnings expectations or a firm reporting a relatively low EPS number. Similar to CEM, research (e.g., Das and Zhang, 2003) reveals that earnings management to round EPS a penny higher rather than lower existed in the U.S. before SOX but mostly evaporated after that (e.g., Jordan et al., 2015).

The peculiar nature of the pandemic-induced recession in 2020 provides a rare opportunity for the reappearance of CEM and/or earnings management enabling EPS to be rounded a cent higher rather than lower. More specifically, the overwhelming changes occurring both in the business environment and in people's personal lives created a scenario where few questions would be asked if a company nudged earnings up a bit. Also, with much of the accounting and internal audit functions performed remotely during this period, internal control procedures may have been relaxed somewhat. Finally, out of necessity, most external auditors had to carry out their audits remotely as well, creating the possibility that something might be missed that is "more easily observable during a site visit" (Tysiac, 2020). The financial watchdogs executing their duties remotely may have allowed the freedom managers needed to be able to manipulate their income upward in response to the financial pressures caused by the pandemic-induced recession in 2020. Thus, the research question or issue in the current study is to ascertain whether evidence exists suggesting that managers engaged in CEM and/or earnings management to round EPS up a cent during 2020 .

\section{METHODOLOGY: TESTING FOR CEM}

The methodology employed in this study in testing for the presence of CEM replicates procedures used in prior research. CEM cannot be ascertained from examining a single firm. Instead, its existence can be established only by looking for data patterns within a large group of companies. Carslaw (1988) notes that CEM is likely present if nines appear as the digit second from the left in the income number inordinately less often than expected while zeros occur in this second digital position much more often than anticipated. All other numbers (one - eight) would be expected to appear in the second position at their normal rates.

Paramount in making this determination is using the relevant expected distributions for the various numbers emerging as the second digit of the income figure. Benford (1938) discovered that for naturally occurring data, numbers do not materialize in the three left digital positions at proportionate rates. Instead, low numbers (e.g., zero, one, two) arise more frequently in these digital positions than high numbers (e.g., seven, eight, nine). Widely recognized as Benford's Law, Table 1 presents the expected distributions of the numerals zero - nine in the three left digital positions of data occurring naturally (i.e., absent human bias).

Benford's Law can be easily demonstrated. For example, the chart in Table 1 indicates that the number two would be expected to appear as the first left digit $17.61 \%$ of the time, while sevens should materialize as the second left digit $9.04 \%$ of the time. Nigrini and Mittermaier (1997) indicate that unmanipulated financial numbers (e.g., balances for accounts receivable, inventory, net income, etc.) should follow Benford's Law. However, they note that if such balances have been deliberately invented or estimated by 
human element (i.e., manipulated), then their digital patterns could deviate from Benford's Law. All previous research examining CEM used Benford's digital distributions as the expected frequencies (e.g., Aono and Guan, 2008; Carslaw, 1988; Guan et al., 2006; Jordan and Clark, 2011; Kinnunen and Koskela, 2003; Lin and Wu, 2014; Skousen et al., 2004; Thomas, 1989; Van Caneghem, 2002). Likewise, the current study employs Benford's expected distributions.

TABLE 1

BENFORD'S DIGITAL FREQUENCIES

\begin{tabular}{|cccc|}
\hline Digit & First & Position of digit in number & \\
& & Second & Third \\
1 & $30.10 \%$ & $11.97 \%$ & $10.18 \%$ \\
2 & 17.61 & 11.39 & 10.14 \\
3 & 12.49 & 10.88 & 10.10 \\
4 & 9.69 & 10.43 & 10.06 \\
5 & 7.92 & 10.03 & 10.02 \\
6 & 6.70 & 9.67 & 9.98 \\
7 & 5.80 & 9.34 & 9.94 \\
8 & 5.12 & 9.04 & 9.90 \\
9 & 4.58 & 8.76 & 9.86 \\
\hline
\end{tabular}

Source: Nigrini \& Mittermaier (1997)

Thomas (1989) tested for CEM in companies with positive income as well as those with negative earnings. Entities with positive income would want to boost earnings so the first earnings digit increases by one, while companies with negative income would do just the opposite (i.e., manipulate earnings so the first number in the net loss figure would be one digit lower). This required testing two distinct samples i.e., one for companies with positive earnings and one for entities with negative income. His findings showed that CEM was much more pronounced for the positive-income firms than for those with negative profits. As a result, many of the ensuing studies on CEM investigated only companies with positive income (e.g., see Jordan and Clark, 2011; Niskanen and Keloharju, 2000; Van Caneghem, 2002). Accordingly, the present study examines only entities that produced positive income. Since the goal is to ascertain whether CEM occurred during the period affected by the pandemic-induced economic downturn, data are collected from COMPUSTAT's Annuals Fundamental file for U.S. companies with year ends from April 2020 through March 2021. Of course, the vast majority of the entities in this time frame had December 31, 2020, year ends, but the above sample period allows for the inclusion of all companies (i.e., even those with fiscal year ends different from the calendar year). Similar to Thomas (1989), the earnings number investigated is income from continuing operations (also referred to as income before discontinued operations).

\section{RESULTS: TESTING FOR CEM}

For U.S. companies appearing in the COMPUSTAT Annuals Fundamental file with year ends from April 2020 through March 2021 (i.e. in essence, the year 2020), 3,322 of them reported positive income. Table 2 provides the details for the analysis of the numbers (zero - nine) emerging as the second left digit in the earnings figure. The first line of data provides the exact count at which each number materialized as the second digit. The next line depicts the frequency at which these numbers showed up in the second position, while the third line provides their expected rates according to Benford's Law. The fourth and fifth lines present the $\mathrm{Z}$ statistic and p-level, respectively, for two-tailed proportions tests measuring the difference between the actual rate for each number and its expected frequency.

As noted earlier, prior research (e.g., Carslaw, 1988; Thomas, 1989; Van Caneghem, 2002) shows that CEM would be indicated in a sample if nines appear at an abnormally lower rate than anticipated as the 
second left digit of the income number while zeros materialize as the second digit at an unusually high rate. All other digits (one - eight) would be expected to emerge at their normal, anticipated frequencies. Table 2 reveals that this phenomenon does not arise during the year of the pandemic. Nines appear as the second digit of the earnings figure at a rate of $8.97 \%$, which does not deviate at a statistically significant level from the anticipated percentage of $8.50 \%$ (i.e., $Z$ statistic of .971 and p-level of .332). Similarly, the actual rate of zeros as the second digit (12.13\%) is not materially different from the expected rate for zeros of $11.97 \%$ (i.e., Z statistic and p-level of .284 and .776, respectively). In fact, the observed rates for all ten digits attune nicely with Benford's frequencies, which suggests the income numbers are naturally occurring and have not been subjected to human bias or intervention, at least as far as CEM is concerned.

\section{TABLE 2 \\ RATES FOR NUMBERS ZERO-NINE APPEARING AS THE SECOND LEFT DIGIT OF INCOME}

\begin{tabular}{|llllllllllll|}
\hline $\mathrm{N}=3,322$ & \multicolumn{8}{c}{ cumber Materializing as the Second Left Digit of Income } \\
& 0 & 1 & 2 & 3 & 4 & 5 & 6 & 7 & 8 & 9 \\
Realized count (n) & 403 & 394 & 362 & 350 & 337 & 313 & 283 & 294 & 288 & 298 \\
Realized rate (\%) & 12.13 & 11.86 & 10.90 & 10.54 & 10.14 & 9.42 & 8.52 & 8.85 & 8.67 & 8.97 \\
Expected rate (\%) & 11.97 & 11.39 & 10.88 & 10.43 & 10.03 & 9.67 & 9.34 & 9.04 & 8.76 & 8.50 \\
Z statistic & 0.284 & 0.853 & 0.037 & 0.207 & 0.211 & -0.488 & -1.624 & -0.382 & -0.183 & 0.971 \\
p-level & .776 & .394 & .970 & .836 & .833 & .626 & .104 & .702 & .855 & .332 \\
\hline
\end{tabular}

\section{METHODOLOGY: TESTING FOR MANIPULATION TO ROUND UP EPS}

As with CEM, the presence of earnings management to boost income so EPS will be rounded up (rather than down) a penny cannot be determined by examining a single firm but rather requires investigating the EPS numbers for a sizable group of entities. In addition, previous research (e.g., Das and Zhang, 2003; Jorgensen, et al., 2014, Miller et al., 2012) suggests that testing for this form of earnings management necessitates more than simply looking at reported EPS numbers but instead requires computing firms' EPS numbers using their income and the average amount of outstanding common shares for the year. As discussed previously, EPS is reported in dollars and cents, but the actual calculated EPS figure rarely falls neatly on the penny mark. Thus, for reporting purposes companies must round computed EPS either up or down a penny based on the number in the third numeral position to the right of the decimal place (hereafter called the $3^{\text {rd }}$ right digit).

Detecting earnings management to enhance income so EPS will be rounded up a penny rather than down a cent requires comparing the actual frequencies of the numbers (zero - nine) occurring as the $3^{\text {rd }}$ right digit of computed EPS to their expected rates. Preeminent in this analysis is ascertaining the correct expected frequencies of the various numbers materializing as the $3^{\text {rd }}$ right digit. As already noted, Benford (1938) showed that the numerals (zero - nine) do not emerge at proportionate rates in the three left digital positions of data that occur naturally but that lower (higher) numbers have a disproportionately greater (lesser) chance of appearing in these digital positions. Furthermore, Pinkham (1961) demonstrated that Benford's expected digital distributions are scale invariant. That is, the expected rates hold true even if data are divided or multiplied by a fixed amount. As an example, assume the data set under investigation is the width, as measured in feet, of each of the rivers in the U.S. at their widest points. This represents naturally occurring data and would be expected to adhere to Benford's Law. Now assume the width of each river as described above is divided by three to convert the measurement from feet to yards; the resulting widths measured in yards would also adhere to Benford's frequencies due to the scale invariance feature.

As Nigrini and Mittermaier (1997) note, unmanipulated financial statement account balances, including net income, should follow Benford's digital distributions. Nonetheless, EPS numbers are not naturally occurring and, thus, would not be expected to obey Benford's Law. This is because EPS results from net income being divided by a nonconstant number (i.e., the average number of outstanding common shares 
differs among each company in a sample). Instead of following Benford's frequencies, research (Das and Zhang, 2003; Jorgensen et al., 2014; Miller et al., 2012) indicates that each numeral (zero - nine) ought to materialize proportionately (i.e., at a 10\% rate) in all the numerical positions extending on the right side of the decimal place in computed EPS.

Accordingly, if earnings are not manipulated, the $3^{\text {rd }}$ right digit of computed EPS should materialize in the range of numbers zero - four at a rate approximating $50 \%$ and in the array of numbers five - nine at a $50 \%$ rate as well. Das and Zhang (2003) note that earnings management to enhance income for the purpose of ensuring that reported EPS is rounded a penny higher rather than lower would be indicated for a sample of entities if the $3^{\text {rd }}$ right digit of computed EPS falls in the array five - nine at a rate significantly higher than $50 \%$ while materializing in the range zero - four at a frequency significantly lower than $50 \%$.

Thomas (1989) shows that manipulation involving earnings rounding occurs much more frequently for companies with positive earnings than for entities producing negative profits. In addition, Miller et al. (2012) present evidence that the motivation to boost income so that EPS will be rounded a penny higher rather than lower increases dramatically the smaller the EPS figure. As an example, increasing EPS from $\$ .08$ to $\$ .09$ improves EPS by $12.5 \%$ while enhancing EPS from $\$ 1.75$ to $\$ 1.76$ raises EPS by only about $.6 \%$. As such, and in keeping with prior research in this area (Jordan et al., 2015; Clark et al., 2019), the current study examines entities with positive EPS between $\$ .01$ and $\$ .99$, inclusive, since these firms would have greater motivation to manage earnings to assure that reported EPS is rounded up a penny than would companies presenting larger EPS figures.

Relevant data for U.S. companies with year ends from April 2020 through March 2021 and with EPS amounts in the range noted above are collected from the COMPUSTAT Annuals Fundamental file. For each entity, its calculated Basic EPS figure is computed by dividing the average amount of outstanding common shares for the year into income from continuing operations; this calculated EPS number is not rounded. The digit in the third numerical position to the right side of the decimal place in this computed EPS figure is then isolated for each company in the sample. The actual rates of the numbers (zero - nine) emerging as the $3^{\text {rd }}$ right digit are then compared to their expected rates to ascertain the presence of earnings management that enables reported EPS to be rounded a cent higher rather than lower.

\section{RESULTS: TESTING FOR MANIPULATION TO ROUND UP EPS}

For the period under study, 877 firms produced EPS amounts between $\$ .01$ and $\$ .99$. Table 3 provides information for the frequencies at which the number in the $3^{\text {rd }}$ right digit of computed EPS falls in the arrays zero - four as well as five - nine. As already noted, prior research that observed earnings management to boost income to ensure EPS is rounded a penny higher rather than lower presented results showing that the $3^{\text {rd }}$ right digit emerged in the five - nine (zero - four) range at a significantly greater (smaller) frequency than should occur by random chance (Das and Zhang, 2003; Jordan, et al., 2015; Jorgensen et al., 2014; Miller et al., 2012). However, the results in Table 3 indicate no such earnings management arose during the period affected by the pandemic-induced economic downturn. In particular, the $3^{\text {rd }}$ right digit materialized as the number zero, one, two, three or four 438 times, which represents $49.94 \%$ of the sample entities. Alternatively, the $3^{\text {rd }}$ right digit appeared as a five, six, seven, eight or nine 439 times (i.e., a rate of $50.06 \%$ ). These frequencies conform almost perfectly to the expected rates for each range assuming random occurrence (i.e., with no earnings management to round EPS up a cent). That is, the actual rates in each range do not deviate significantly from the anticipated rate of $50 \%$ (i.e., $Z$ statistic and p-level for proportions test of .036 and .971, respectively). 


\section{TABLE 3 \\ $3^{\text {rd }}$ RIGHT DIGIT RATES IN ZERO-FOUR AND FIVE-NINE RANGES FOR CALCULATED EPS}

\begin{tabular}{|c|c|c|}
\hline \multirow[t]{2}{*}{$\mathrm{N}=877$} & \multicolumn{2}{|c|}{$\underline{3^{\text {rd }} \text { Right Digit Range }}$} \\
\hline & zero - four & five - nine \\
\hline Realized count (n) & 438 & 439 \\
\hline Realized rate $(\%)$ & 49.94 & 50.06 \\
\hline Expected rate $(\%)$ & 50.00 & 50.00 \\
\hline Z statistic & -0.036 & 0.036 \\
\hline p-level & .971 & .971 \\
\hline
\end{tabular}

In addition to examining the frequencies at which the numbers in the $3^{\text {rd }}$ right digit of computed EPS emerged in the spectrums zero - four and five - nine, Das and Zhang (2003) and Jordan et al. (2015) tested for earnings management enabling EPS to be rounded up (instead of down) a penny by also investigating the rates at which each individual number zero - nine materialized as the $3^{\text {rd }}$ right digit. As mentioned earlier, in the absence of manipulation, each number zero - nine should emerge as the $3^{\text {rd }}$ right digit at about a $10 \%$ rate.

In their sample data from 1989-1998 (i.e., pre-SOX years), Das and Zhang (2003) found an additional anomaly providing more evidence of earnings management aimed at rounding EPS up a penny. More specifically, they discovered that a material break or discontinuity existed with fours in that far less fours emerged as the $3^{\text {rd }}$ right digit relative to what was expected. The traditional minimal threshold in the $3^{\text {rd }}$ right digit for rounding EPS up a cent is a five. Das and Zhang (2003) speculated that the under abundance of fours occurred because as the $3^{\text {rd }}$ right digit nears the minimum threshold for rounding EPS up a cent (i.e., five), the easier and more likely it would be for managers to boost income to ensure the rounding up (instead of down) of reported EPS. Jordan et al. (2015) observed a similar finding in their pre-SOX (19972000) sample i.e., a discontinuity with significantly fewer fours than expected as the $3^{\text {rd }}$ right digit of calculated EPS. In their post-SOX (2003-2012) sample, however, this data anomaly disappeared as each number zero - nine emerged as the $3^{\text {rd }}$ right digit at about its anticipated rate (i.e., $10 \%$ ).

The current study also examines the frequencies at which each number zero - nine materialized as the $3^{\text {rd }}$ right digit of computed EPS for the period affected by the pandemic. Table 4 presents the results of this test and reveals no compelling signs of any data aberration that would suggest earnings were manipulated upward to enable EPS to be rounded a cent higher rather than lower.

\section{TABLE 4 \\ RATES FOR NUMBERS ZERO-NINE OCCURRING AS $3^{\text {rd }}$ RIGHT DIGIT IN CALCULATED EPS}

\begin{tabular}{|lllllllllll|}
\hline $\mathrm{N}=877$ & & & \multicolumn{8}{c|}{ Number Appearing as $3^{\text {rd }}$ Right Digit } \\
& 0 & 1 & 2 & 3 & 4 & 5 & 6 & 7 & 8 & 9 \\
Realized count (n) & 87 & 92 & 93 & 90 & 76 & 88 & 79 & 88 & 97 & 87 \\
Realized rate (\%) & 9.92 & 10.49 & 10.60 & 10.26 & 8.67 & 10.03 & 9.01 & 10.03 & 11.06 & 9.92 \\
Expected rate (\%) & 10.00 & 10.00 & 10.00 & 10.00 & 10.00 & 10.00 & 10.00 & 10.00 & 10.00 & 10.00 \\
Z statistic & -.0 .079 & 0.484 & 0.592 & 0.257 & -1.313 & 0.030 & -0.977 & 0.030 & 1.046 & -0.079 \\
p-level & .937 & .628 & .554 & .797 & .189 & .976 & .329 & .976 & .296 & .937 \\
\hline
\end{tabular}

More specifically, every number zero - nine occurs as the $3^{\text {rd }}$ right digit of computed EPS at approximately its expected rate of $10 \%$. That is, no p-level for any number zero - nine reveals a difference between its actual rate of occurrence and the anticipated rate of $10 \%$ that would be considered statistically significant by traditional measures of significance. This lends further credence to the finding that during 
the pandemic, managers did not appear to engage in earnings manipulation that allows reported EPS to be rounded a penny higher rather than lower.

\section{SUMMARY AND CONCLUSION}

This study examines two specific types of accrual-based earnings management that existed prior to SOX but largely faded away thereafter. The first one, commonly referred to as CEM, occurs when the second left digit in the income number is large (i.e., nine) and managers boost income by the small amount needed for this digit to reach zero, thereby causing the first left income digit to increase by one. The second type arises when management enhances income by a relatively minor amount to ensure that calculated EPS is rounded up a penny, rather than down a cent, when the EPS figure is reported in the income statement.

Even though both types of earnings management generally vanished after SOX, research suggests that earnings management activities frequently increase during periods of economic stress (Trombetta and Imperatore, 2014; Wang and Huang, 2014). Virtually overnight, the COVID-19 pandemic created a rise in the U.S. unemployment rate to a point not experienced since the Great Depression (i.e., from 3.5\% in February 2020 to $14.8 \%$ just two months later). Although the unemployment rate fell steadily during 2020 from its zenith in April, it remained elevated at year's end at over twice its pre-pandemic rate.

The research issue examined in the current study is if one or both of these types of earnings rounding manipulation techniques would reemerge during the pandemic year (2020). Even though both types of earnings management require only small boosts to income and, thus, are relatively easy to achieve, the evidence presented here suggests neither of them occurred in general during 2020. These results are quite heartening considering the status of the financial reporting process in this country a little over two decades ago when SEC Chairman at the time, Arthur Levitt, noted that the process had "evolved into a 'game' among the market participants, a sport of nods and winks" (Munter, 1999, p. 31). By the year 2000, earnings management in the U.S. had become unbridled and culminated in the huge financial frauds that came to light soon thereafter (e.g., Enron, WorldCom, HealthSouth, etc.).

Of course, the resultant SOX legislation was designed and implemented in 2002 in an attempt to curtail earnings management in this country and restore public confidence in the financial reporting system. As noted previously, significant research conducted soon after SOX became effective indicates the legislation had its intended effect, at least in terms of reducing the incidence and severity of various forms of earnings management. As Ketz (1999) notes, however, the seemingly anything-goes financial reporting system that had developed by the late 1990s had its roots in changing cultural values where "certain segments of society have begun to assault the traditional values of truth and integrity" (Ketz, 1999, p. 41). Simply enacting legislation aimed at curtailing fraudulent financial reporting, though, could not necessarily be expected to swing cultural values back in the proper direction. Doing this would require a change in the mindset of those involved in the financial reporting process, and such a change in mindset would be difficult to ascertain. Nevertheless, the findings in this study provide anecdotal evidence that perhaps the pendulum that represents our society's cultural values has swung back to the side of truth and integrity, at least with respect to financial reporting.

\section{LIMITATIONS}

The results here suggesting the two types of earnings management investigated did not return during the pandemic-induced economic downturn of 2020 represent an overall finding. Nonetheless, as Guckes (2020) indicates, the financial distress experienced in 2020 varied widely among industries. Companies operating in industries harder hit by the downturn likely had more motivation to manage earnings than did entities in industries that were only mildly effected. Plus, research shows that even in normal times, the propensity to manipulate earnings differs among industries. Numerous studies reveal that entities operating in industries experiencing profound market competition are more apt to partake in accrual-based earnings management than are those operating in industries with less competition (e.g., Datta et al., 2013; Tang and Chen, 2020; Zhang et al., 2017). The findings in the present study might have been different if industry 
effects had been examined. Performing an industry analysis was not possible though because the tests applied here required larger sample sizes than were available within individual industries.

As noted previously, research indicates that the two types of earnings management activities examined in this study existed prior to SOX but disappeared in general afterward. Yet, a couple of studies tested for these earnings management practices in the post-SOX period but segregated their samples by entity size (Jordan et al., 2019; Jordan et al. 2017). They found that while both forms of earnings management had vanished overall (i.e., for the full sample of firms) and for most of the subsamples separated by company size, both types still appeared to be practiced by small entities. The goal of the current study was to ascertain whether either of these earnings management techniques reemerged for the general population of companies during the pandemic year (2020). Thus, the samples here were not partitioned by entity size since extant research had already demonstrated the continued presence of both forms of earnings management for small firms in the post-SOX years.

Finally, even though the recession in 2020 was steep, it was relatively short. Rupkey (2020) notes that using employment numbers to gauge the beginning and ending points of the recession, it appears the pandemic-driven recession lasted about two months. Thus, in terms of length, the 2020 recession pales in comparison to the Great Recession of 2007-2008 that lasted 18 months. There exists, of course, a possibility that CEM and/or earnings management to boost income so EPS would be rounded up a penny might have reappeared if the COVID-19 related recession had been longer in duration. Notwithstanding, this study accomplishes its stated objective and provides evidence suggesting that these two forms of earnings management activities did not occur overall during the unique, pandemic-driven 2020 economic downturn.

\section{REFERENCES}

Anin, R. (2021). Securitization and earnings management: Evidence from the Sarbanes-Oxley Act. Journal of Financial Regulation and Compliance, 29(1), 44-62.

Aono, J., \& Guan, L. (2008). The impact of the Sarbanes-Oxley Act on cosmetic earnings management. Research in Accounting Regulation, 20, 205-215.

Aubert, F., \& Grudnitski, G. (2014). The impact of SOX on opportunistic management behavior. International Review of Financial Analysis, 32, 188-198.

Benford, F. (1938). The law of anomalous numbers. Proceedings of the American Philosophical Society, $78(4), 551-572$.

Brenner, G., \& Brenner, R. (1982). Memory and markets, or why are you paying $\$ 2.99$ for a widget? Journal of Business, 55(1), 147-158.

Carslaw, C. (1988). Anomalies in income numbers: Evidence of goal oriented behavior. The Accounting Review, 63(2), 321-327.

Clark, S., Jordan, C., \& Simmons, V. (2019). Earnings management to round up EPS a penny: Testing for an audit quality differential between Big-four and NonBig-four accounting firms. Journal of Forensic and Investigative Accounting, 11(2), 248-260.

Congressional Research Service. (2021, January 12). Unemployment rates during the COVID-19 pandemic. In Brief, pp. 1-16.

Das, S., \& Zhang, H. (2003). Rounding-up in reported EPS, behavioral thresholds, and earnings management. Journal of Accounting and Economics, 35(1), 31-50.

Datta, S., Iskandar-Datta, M., \& Singh, V. (2013). Product market power, industry structure, and corporate earnings management. Journal of Banking and Finance, 37(8), 3273-3285.

Guan, L., He, D., \& Yang, D. (2006). Auditing, integral approach to quarterly reporting, and cosmetic earnings management. Managerial Auditing Journal, 21(6), 569-581.

Guckes, M. (2020). Unique recession impacts market segments differently. Production Machining, 20(12), 38-41.

Hossain, M., Mitra, S., Razaee, Z., \& Sarath, B. (2011). Corporate governance and earnings management in the pre- and post-Sarbanes-Oxley Act regimes: Evidence from implicated option backdating firms. Journal of Accounting, Auditing \& Finance, 26(2), 279-315. 
Jordan, C., \& Clark, S. (2011). Detecting cosmetic earnings management using Benford's Law. The CPA Journal, 81(2), 32-37.

Jordan, C., \& Clark, S. (2015). The effect of the Sarbanes-Oxley Act on cosmetic earnings management: Additional evidence. Oil, Gas \& Energy Quarterly, 63(4), 639-650.

Jordan, C., Clark, S., \& Pate, G. (2015). Earnings management to report an additional cent of EPS: Evidence from pre- and post-SOX periods. Academy of Accounting and Financial Studies Journal, 19(3), 153-163.

Jordan, C., Clark, S., \& Simmons, V. (2019). Earnings management to round EPS up a cent: An examination of company size in the post-SOX era. Journal of Business and Economic Perspectives, 46(1), 10-29.

Jordan, C., Hatten, A., \& Clark, S. (2017). Cosmetic earnings management in the post-SOX period: An analysis of entity size. Journal of Accounting and Finance, 17(6), 59-68.

Jorgensen, B., Lee, Y., \& Rock, S. (2014). The shapes of scaled earnings histograms are not due to scaling and sample selection: Evidence from distributions of reported earnings per share. Contemporary Accounting Research, 31(2), 498-521.

Ketz, E. (1999). Update: How goes SEC's war against earnings management. Journal of Corporate Accounting and Finance, 10(3), 41-52.

Kinnunen, J., \& Koskela, M. (2003). Who is Miss World in cosmetic earnings management? A crossnational comparison of small upward rounding of net income numbers among eighteen countries. Journal of International Accounting Research, 2, 39-68.

Lin, F., \& Wu, S. (2014). Comparison of cosmetic earnings management for the developed markets and emerging markets: Some empirical evidence from the United States and Taiwan. Economic Modelling, 36, 466-473.

Miller, P., Martin, G., \& Bahnson, P. (2012). A penny for your thoughts: Sizing up manipulative EPS rounding. Strategic Finance, 94(1), 35-39.

Munter, P. (1999). SEC sharply criticizes "earnings management" accounting. Journal of Corporate Accounting and Finance, 10(2), 31-38.

Nigrini, M., \& Mittermaier, L. (1997). The use of Benford's Law as an aid in analytical procedures. Auditing: A Journal of Practice \& Theory, 16(2), 52-67.

Niskanen, J., \& Keloharju, M. (2000). Earnings management in a tax-driven accounting environment: Evidence from Finnish public firms. European Accounting Review, 9, 443-452.

Pinkham, R. (1961). On the distribution of first significant digits. Annals of Mathematical Statistics, 32, $1223-1230$.

Rupkey, C. (2020, June). COVID-19's economic effects. Secured Lender, pp. 48-48.

Skousen, C., Guan, L., \& Wetzel, T. (2004). Anomalies and unusual patterns in reported earnings: Japanese managers round earnings. Journal of International Financial Management \& Accounting, 15(3), 212-234.

Tang, H., \& Chen, A. (2020). How do market power and industry competition influence the effect of corporate governance on earnings management? Quarterly Review of Economics and Finance, $78,212-225$.

Thomas, J. (1989). Unusual patterns in reported earnings. The Accounting Review, 64(4), 773-787.

Trombetta, M., \& Imperatore, C. (2014). The dynamic of financial crisis and its non-monotonic effects on earnings quality. Journal of Accounting and Public Policy, 33(3), 205-232.

Tysiac, K. (2020, March 24). Remote auditing comes to forefront during pandemic. Journal of Accountancy Online. Retrieved from journalofaccountancy.com

Van Caneghem, T. (2002). Earnings management induced by cognitive reference points. British Accounting Review, 34(2), 167-178.

Wang, Y., \& Huang, P. (2014). Earnings manipulation and profitability. Economic Computation and Economic Cybernetics Studies and Research, 48(1), 1-22.

Zhang, T., Zeng, W., Zhong, R., \& Li, Y. (2017). Industry competition in China: An external governance mechanism or an external incentive. Asian-Pacific Economic Literature, 31(2), 123-136.

10 Journal of Applied Business and Economics Vol. 23(5) 2021 